\title{
Formation of nanocrystalline titanium carbonitride by pyrolysis of poly(titanylcarbodiimide)
}

\author{
O. Lichtenberger ${ }^{\mathrm{a}}$, E. Pippel ${ }^{\mathrm{a}}$, J. Woltersdorf ${ }^{\mathrm{a}, *}$, R. Riedel $^{\mathrm{b}}$ \\ a Max-Planck-Institut für Mikrostrukturphysik, Weinberg 2, D-06120 Halle, Germany \\ ${ }^{\mathrm{b}}$ Fachgebiet Disperse Feststoffe, Institut für Materialwissenschaft, TU Darmstadt, Petersenstr. 23, D-64287 Darmstadt, Germany
}

Received 11 February 2003; received in revised form 6 March 2003; accepted 29 March 2003

\begin{abstract}
The chemical formation of advanced ceramics from organometallic precursors is promising with respect to structural design and tailormade properties. We report on the synthesis of nanocrystalline titanium carbonitride materials at different pyrolysis temperatures via the polymer-to-ceramic transformation of synthesised poly(titanylcarbodiimides) and their structural and nanochemical characterization using high-resolution and analytical electron microscopy, in combination with quantummechanical calculations. Pyrolysis at $800{ }^{\circ} \mathrm{C}$ leads to a mixture of amorphous carbon and titanium nitride as crystalline particles of about $4 \mathrm{~nm}$ in size. Pyrolysis at $1100{ }^{\circ} \mathrm{C}$ yields titanium carbonitride as crystalline particles of $20-30 \mathrm{~nm}$ in size. The identification of all phases was possible by the analysis of the measured energy-loss near-edge spectra of their $\mathrm{C}-\mathrm{K}$ and $\mathrm{N}-\mathrm{K}$ edges, and comparison with measured standards and with simulated fine structures using calculations based on the density functional theory.
\end{abstract}

(C) 2003 Elsevier Science B.V. All rights reserved.

Keywords: Organometallic precursors; Preceramic polymers; Titanium carbonitride; High-resolution electron microscopy; Electron energy-loss spectroscopy; Energy-loss near-edge structure

\section{Introduction}

The development of advanced ceramic materials for special applications (coatings, fibres, bioceramics, sensors, electronic devices) also demands the involvement of multiphase polycrystalline composite materials consisting of, e.g. binary and ternary carbides, nitrides or carbonitrides. Due to the thermal instability of the corresponding solid solutions, a microstructural design and a systematic optimisation of such ceramic materials is beyond the possibilities of the traditional high-temperature synthesis methods via solid-state reactions.

In the last decade, as an alternative processing, the chemical formation of advanced multielement ceramics by polymer pyrolysis has been established [1-4]: novel materials of this kind can be built up from molecular units called precursors, especially in the ternary $\mathrm{Si}-\mathrm{C}-\mathrm{N}$ and $\mathrm{Ti}-\mathrm{C}-\mathrm{N}$ and in the quaternary $\mathrm{Si}-\mathrm{B}-\mathrm{C}-\mathrm{N}$ and $\mathrm{Ti}-\mathrm{B}-\mathrm{C}-\mathrm{N}$ systems. These units must be cross-linked with each other by appropriate processing steps via a polymerisation process yielding a preceramic polymer. A subsequent thermal

\footnotetext{
* Corresponding author. Tel.: +49-345-558-2922; fax: +49-345-551-1223.

E-mail address: wolt@mpi-halle.de (J. Woltersdorf).
}

treatment denoted as thermolysis or pyrolysis transforms this polymer into the ceramic material.

It is essential in this method that the mechanical, thermal, and functional properties of the final materials strongly depend on the structure and on the chemistry of the molecular units as well as on the polymerisation and pyrolysis procedure. Therefore, this processing route enables a molecular design and, as a result, a real tayloring of materials. Further advantages are (i) the high purity of the products as no sintering additives are necessary, (ii) a homogeneous distribution of the elements down to atomic dimensions, and (iii) relatively low processing temperatures between 800 and $1200^{\circ} \mathrm{C}$ as compared to the sintering temperatures of the conventional methods $\left(>1400^{\circ} \mathrm{C}\right)$. Of course, for tayloring the material properties, the starting components and the intermediate products have to be optimised with respect to their composition, purity, reactivity, and transformation kinetics. All these parameters including special catalysts and fillers and the different processing conditions strongly influence the phase composition and microstructure of the final materials.

Especially, $\operatorname{TiC}_{x} \mathrm{~N}_{y}$ phases $(x+y=1)$ are characterised by high hardness, electrical conductivity, wear resistance and chemical inertness. Usually, polycrystalline titanium carbonitride is obtained by the reaction of titanium carbide 
with nitrogen at temperatures around $1800^{\circ} \mathrm{C}$ [5] or, in case of thin layers, by chemical and physical vapour deposition technology [6].

In a foregoing paper [7] we presented general reaction conditions for the synthesis and the characterisation of the Ti-C-N-precursor by infrared absorption and Raman spectroscopy, and of the ceramic material by X-ray powder diffraction. In this paper, we report on the synthesis of nanocrystalline titanium carbonitride materials at different pyrolysis temperatures via the polymer-to-ceramic transformation [8-10] of a newly developed titaniumcarbodiimide polymer [7] and their structural and nanochemical characterisation using high-resolution and analytical electron microscopy in combination with quantummechanical calculations.

\section{Experimental}

\subsection{Production of the carbonitridic samples}

The preceramic polymeric titanium carbodiimide was obtained by the reaction of bis(trimethylsilyl)carbodiimide with titanium tetrachloride:

$$
\mathrm{TiCl}_{4}+2\left(\mathrm{CH}_{3}\right)_{3} \mathrm{Si}-\mathrm{N}=\mathrm{C}=\mathrm{N}-\mathrm{Si}\left(\mathrm{CH}_{3}\right)_{3}
$$

The educt bis(trimethylsilyl)carbodiimide was synthesised by the reaction of hexamethyl-disilazane with dicyandiamide and catalytic amounts of ammonium sulphate $[11,12]$ followed by distillation under argon on normal pressure conditions. For the preparation of poly(titanylcarbodiimide) according to Eq. (1), a solution of $100 \mathrm{ml}$ $(440 \mathrm{mmol})$ bis(trimethylsilyl)carbodiimide in $100 \mathrm{ml}$ dry toluene (FLUKA, puriss., abs., over molecular sieve) was cooled to $0{ }^{\circ} \mathrm{C}$ in an appropriate reaction vessel, connected with a reflux condenser, in an ice/water bath. The air in the reaction vessel was replaced by argon. A solution of $18 \mathrm{ml}(130 \mathrm{mmol})$ of titanium tetrachloride (FLUKA, purum, $\geq 98.0 \%$, freshly distilled) in $90 \mathrm{ml}$ dry toluene was added dropwise while stirring, cooling, and argon flow. During the addition of the $\mathrm{TiCl}_{4}$ solution a yellow-orange precipitate was formed. The reaction mixture was stirred at $0{ }^{\circ} \mathrm{C}$ for $6 \mathrm{~h}$ and for $12 \mathrm{~h}$ at room temperature under argon. Afterwards the reaction mixture was refluxed for $5 \mathrm{~h}$, whereby it became a dark red suspension. The liquid components chlorotrimethylsilane, toluene and the excess bis(trimethylsilyl)carbo-diimide were removed under reduced pressure at $80^{\circ} \mathrm{C}$ using a rotary evaporator. The remaining dark red powdery solid was dried at $90{ }^{\circ} \mathrm{C}$ under $10 \mathrm{mbar}$ for $2 \mathrm{~h}$. Afterwards the vessel was ventilated with argon. The polymeric powder was subsequently crosslinked at $200^{\circ} \mathrm{C}$ for $1.5 \mathrm{~h}$ under argon.

Samples of $400 \mathrm{mg}$ of the cross-linked poly(titanylcarbodiimide) have been placed in a small silica sample dish under argon and heated in a tubular oven with a heating rate of $200{ }^{\circ} \mathrm{Ch}^{-1}$ under an argon flow-through of $20 \mathrm{lh}^{-1}$. After $2 \mathrm{~h}$ at 800 or $1100^{\circ} \mathrm{C}$, respectively, the samples were slowly temperature-controlled cooled down at $200^{\circ} \mathrm{Ch}^{-1}$. In order to reduce the oxygen partial pressure during annealing, an array of tantalum plates has been placed in the tubular oven, near the silica dish. The oxygen partial pressure was measured during the annealing process, using an oxygen sensitive electrode. It has never exceeded $3 \times 10^{-11} \mathrm{~Pa}\left(\right.$ at $\left.800{ }^{\circ} \mathrm{C}\right)$ or $5 \times 10^{-10} \mathrm{~Pa}\left(\right.$ at $1100^{\circ} \mathrm{C}$ ), respectively.

\subsection{HREM and EELS investigations}

In order to study the microstructure, the composition, and the nature of the bonds of the pyrolysed samples, investigations were performed by transmission electron microscopy (TEM) including high-resolution or atomic plane imaging (HREM) and electron energy-loss spectroscopy (EELS), especially the measurement of the fine structure of the EELS signals near the ionisation edge (ELNES) [13-16].

The EELS method allows to estimate the species and concentration of the chemical elements with a spatial resolution limited by the diameter of the measuring probe (1-2 nm). Moreover, by analysing the ELNES features of the relevant ionisation edges, it is possible to characterise the chemical bonding state of individual elements with the same local resolution, provided, the energy resolution is better than $1 \mathrm{eV}$. The ELNES is caused by excitations of core-shell electrons into unoccupied states above the Fermi level, and thus, the measured intensities give information on the partial local density of states (PLDOS) which is representative of the bonding state of the atom. The characteristic ELNES details are the edge onset as well as the shape, the position, and the intensity of individual peaks in the fine structure. We interpret the measured ELNES features by comparison with adequate quantummechanical calculations of the ELNES which are described in the next section.

The recorded EEL spectra additionally were used for a quantitative elemental analysis after background subtraction via the Hartree-Slater model, considering an integration width of $50 \mathrm{eV}$ after each ionisation edge. For this quantitative analysis the computer program EL/P by Gatan was used.

\section{Quantummechanical calculations}

Simple clusters, simulating amorphous titanium carbodiimide and the crystal structures of TiC, TiN and a hypothetical titanium carbonitride $\mathrm{TiC}_{0.5} \mathrm{~N}_{0.5}$ have been used, 
considering the correct octahedral co-ordination of the central titanium atom (examples for structural models [17]). At first, a quantumchemical calculation using the semiempirical PM3(tm)-method (parameterised method 3 for transition metals [18]) with consideration of all valence electrons, including d-electrons, with geometry optimisation has been performed, in order to obtain cluster geometries with minimised formation enthalpy. Afterwards a DFT (density functional theory) calculation of the so optimised molecule was carried out, using a double numerical basis set with polarisation functions [22]. For our calculations, the program SPARTAN, version 5 (Wavefunction, Inc., Irvine, California) has been used.

The ELNES of the $\mathrm{C}-\mathrm{K}, \mathrm{N}-\mathrm{K}$, and Ti-L edges have been simulated in two steps:

1. After the quantumchemical calculation based on the LCAO approach (linear combination of atomic orbitals) and described as

$\Psi_{i}=\sum_{\lambda=1}^{n} c_{i \lambda}^{2} \varphi_{\lambda}$

where $\varphi_{\lambda}$ are atomic wave functions, $c_{i \lambda}$ the orbital coefficients, and $\Psi_{I}$ the wavefunctions of the molecular orbitals, the partial local densities of the unoccupied electronic states above the Fermi-level, localised at the interesting atom (PLDOS), have been calculated using the relation

$\rho_{\mathrm{spd}}^{i}(E)=\sum_{E}^{E+\Delta E} \sum_{k=j}^{j+8} c_{i k}^{2}$

i.e. by summing up the squares of the orbital coefficients (which represent the occupation densities of the corresponding electron levels) in equidistant energy intervals. Here, $k=j$ yields s-like, $k=j+1, \ldots, j+3$ p-like, and $k=j+4, \ldots, j+8$ d-like partial local densities, respectively $[19,20]$. The energy interval $\Delta E$ has been chosen to $0.5 \mathrm{eV}$, adjusted corresponding to the energy filter used in TEM.

2. The discrete peaks of the PLDOS, obtained in this manner, are convoluted with Gauss functions, whose width are determined by the finite lifetime of the end states [13]. The values are calculated in energy steps of $0.1 \mathrm{eV}$, output as ASCI table and graphically represented using appropriate software.

\section{Results and discussion}

\subsection{Morphology and nanochemistry of the materials}

After cross-linking at $200{ }^{\circ} \mathrm{C}$ the polymeric titanium carbodiimide appears as an amorphous powder. Electron micrographs at high magnification as well as the electron diffraction pattern indicate only amorphous regions in the corresponding particles of different sizes. A quantitative element analysis of this material by EELS reveals oxygen and chlorine, besides the expected elements titanium, carbon and nitrogen. Despite the nearly two-fold molar excess of bis(trimethylsilyl)carbodiimide in the synthesis of the polymer, some chlorine atoms of the educt titanium tetrachloride are still present in form of end groups (cf. Fig. 1). As metal carbodiimides are known to be very oxygen- and moisture-sensitive [10,21], the relatively high oxygen content analysed is due to contamination by manipulation of the material in air.

The sample pyrolysed at $800{ }^{\circ} \mathrm{C}$ shows small crystalline particles of $4-5 \mathrm{~nm}$ in size. The lattice spacings of these nanocrystalline particles, imaged by high resolution electron microscopy (Fig. 2a), as well as the electron diffraction pattern indicate the existence of almost cubic titanium nitride. The analysis of the $\mathrm{C}-\mathrm{K}$ and N-K ELNES of these particles confirms this assumption (see below). Carbon

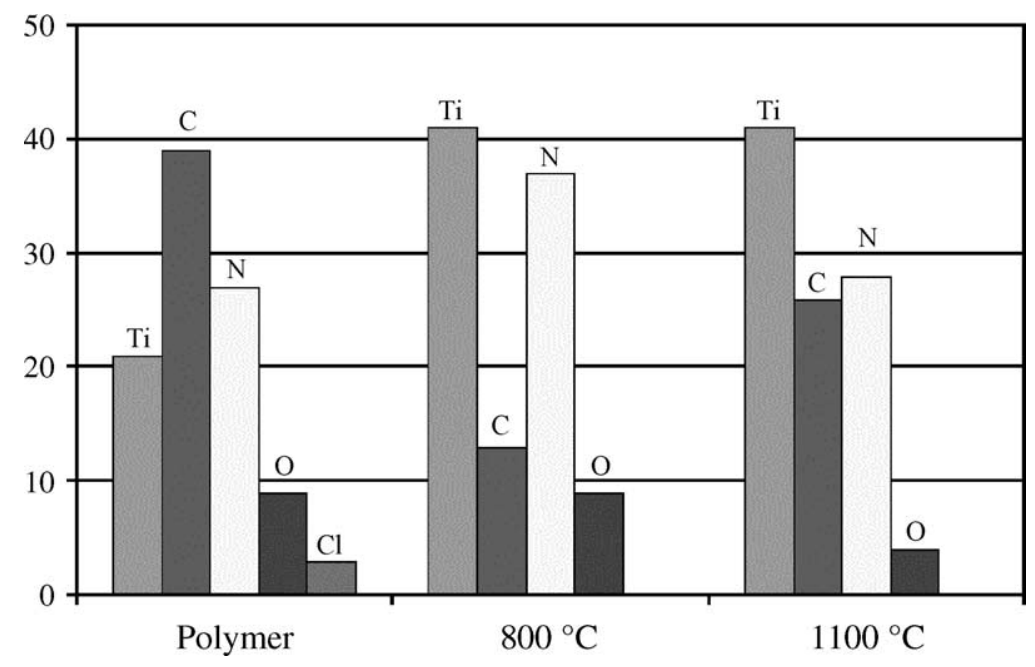

Fig. 1. Quantitative elemental analysis (concentration in at.\%) of poly(titanylcarbodiimide) and two pyrolised samples, derived from EEL spectra. 

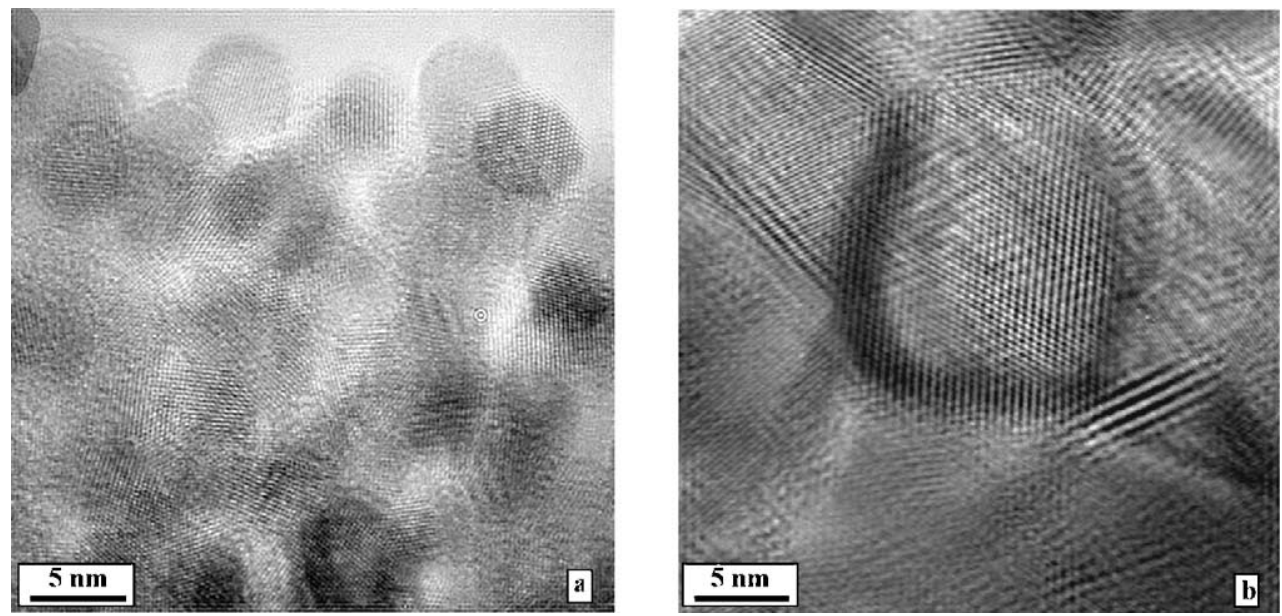

Fig. 2. HREM images of poly(titaniumcarbodiimide) pyrolysed at (a) $800^{\circ} \mathrm{C}$ and (b) $1100^{\circ} \mathrm{C}$.

is found predominantly as amorphous carbon in the regions between the crystallites, and marginally bound as carbide in the crystallites. The relative small amount of carbon in this material (Fig. 1) indicates the high loss of carbon containing molecular fragments during pyrolysis (mainly $\mathrm{HCN}, \mathrm{CH}_{4}, \mathrm{CH}_{3} \mathrm{CN}$, and $\left(\mathrm{CH}_{3}\right)_{3} \mathrm{SiOSi}\left(\mathrm{CH}_{3}\right)_{3}$ ), which we reported previously [7], investigated by thermal gravimetric analysis and simultaneous mass spectrometry.

The sample pyrolysed at $1100{ }^{\circ} \mathrm{C}$ shows crystallites of significantly larger size (about $20-30 \mathrm{~nm}$ in diameter, cf. Fig. 2b) with almost no amorphous carbon in between the particles. As the EELS analysis of all of these single crystals reveals the concomitance of carbon and nitrogen in the molar ratio of about 1:1 (cf. Fig. 1), the existence of titanium carbonitride of the stoichiometric composition $\mathrm{TiC}_{0.5} \mathrm{~N}_{0.5}$ is suggested. This assumption was also proven by a more detailed ELNES analysis of the $\mathrm{C}-\mathrm{K}$ ionisation edge (cf. next section). Both pyrolysed samples did not show any hints of chlorine content.

\subsection{Bond analyses by ELNES of the $C-K$ and $\mathrm{N}-\mathrm{K}$ edges}

The ELNES of both the $\mathrm{C}-\mathrm{K}$ and $\mathrm{N}-\mathrm{K}$ edges of the polymeric titanylcarbodiimide, given in Fig. 3, is characterised by a sharp peak with high intensities at about 288 and $400 \mathrm{eV}$, respectively. As shown by the calculations (see below, and cf. Fig. 4), these peaks are caused by excitation of core 1s-electrons into unoccupied energy levels above the

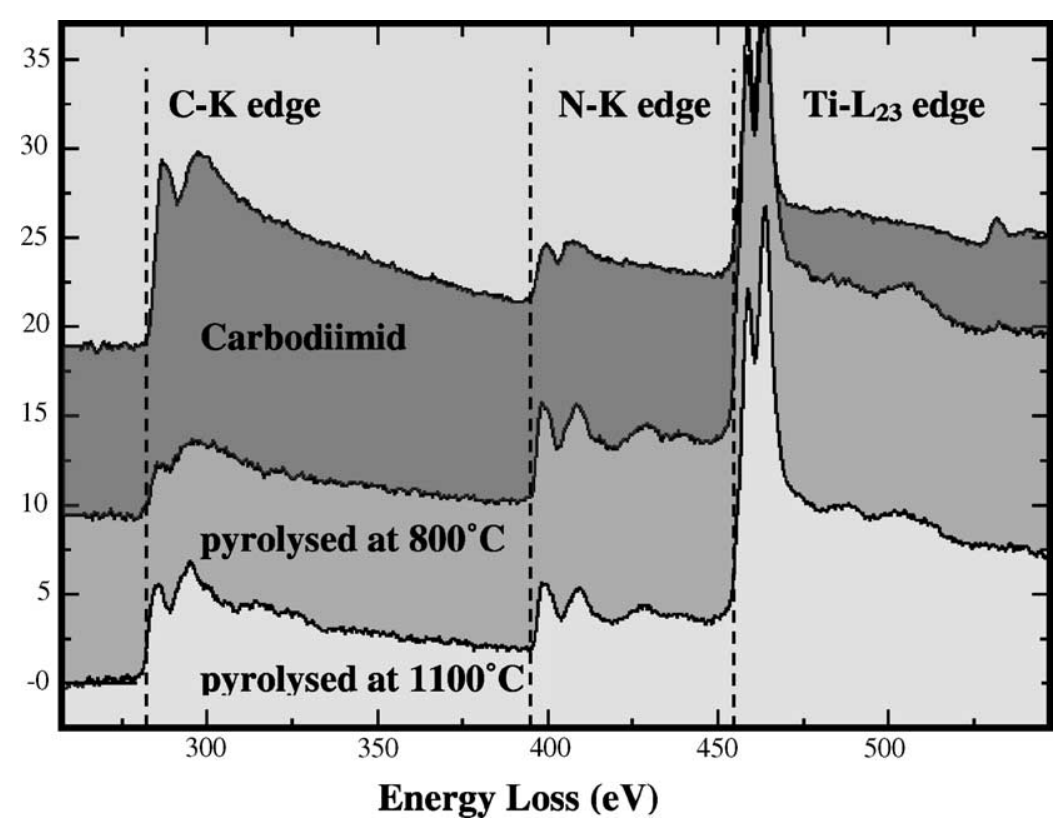

Fig. 3. EEL spectra of poly(titanylcarbodiimide) and its pyrolysis products at 800 and $1100^{\circ} \mathrm{C}$ (measured in arbitrary units). 


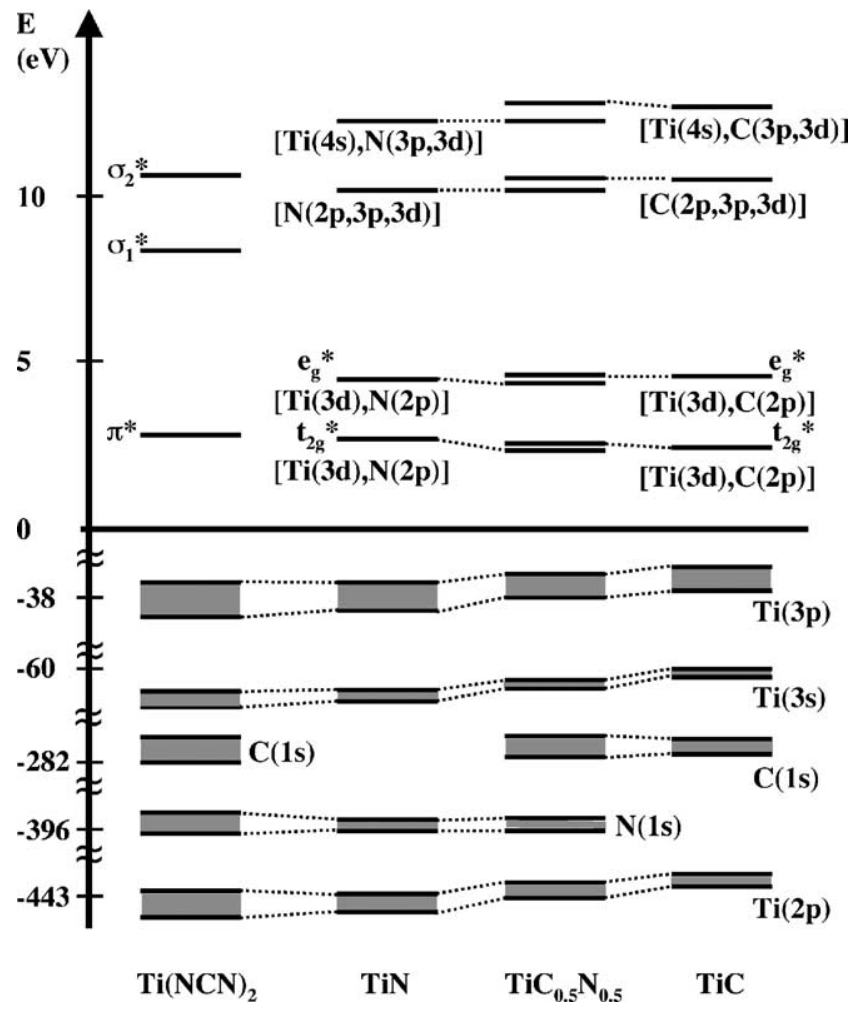

Fig. 4. MO scheme for different titanium compounds, derived by DFT calculations. Valence- and core-levels are broadened into bands due to electron-electron-interactions and correlation effects.

Fermi energy with $\pi^{*}$-character: the high occupation density and the pronounced $\pi^{*}$-character of these levels, consisting mainly of $\mathrm{C}\left(2 \mathrm{p}_{\mathrm{z}}\right)$ and $\mathrm{N}\left(2 \mathrm{p}_{\mathrm{z}}\right)$ orbitals with contributions of $\mathrm{Ti}(4 \mathrm{~s})$ and $\mathrm{Ti}(3 \mathrm{~d})$ orbitals, give rise to the high intensity of this first main peak observed in the $\mathrm{C}-\mathrm{K}$ and $\mathrm{N}-\mathrm{K}$ ELNES. The strong intensity of this peak, in comparison to other carbon or nitrogen containing compounds, seems to be of high specificity for the electronic structure of carbodiimides, indicating the markedly double bound character of the carbodiimide bond $(-\mathrm{N}=\mathrm{C}=\mathrm{N}-)$ as we have shown in [22]. The subsequent double peak in the C-K ELNES at about $300 \mathrm{eV}$ and in the N-K ELNES at about $408 \mathrm{eV}$ can be interpreted as excitation of $1 \mathrm{~s}$ core electrons into unoccupied levels with $\sigma^{*}$-character.

The splitting of the $\sigma^{*}$-like unoccupied levels (cf. Fig. 7, upper curve) are due to a cancellation of the degeneration of the Ti-p-levels involved and are in good agreement with the MO (molecular orbital)-scheme derived by DFT calculations and presented in Fig. 4. In contrast to most crystalline materials, pronounced broad peaks attributed to inner well resonances are not detected in both $\mathrm{C}-\mathrm{K}$ and $\mathrm{N}-\mathrm{K}$ ELNES of polymeric titanylcarbodiimides.

After pyrolysis at $800^{\circ} \mathrm{C}$ the ELNES of both edges changes as demonstrated in Fig. 3: the first peak of the $\mathrm{C}-\mathrm{K}$ edge shifts to $285 \mathrm{eV}$, and its intensity decreases considerably, most likely due to the break of double bonds between carbon and nitrogen in the carbodiimide bond. The ELNES of the C-K-edge after pyrolysis at $800^{\circ} \mathrm{C}$ essentially resembles that of amorphous carbon. The $\mathrm{N}-\mathrm{K}$ edge indicates the existence of titanium nitride, confirmed by both the comparison with the measured EEL spectrum of a TiN standard, shown in Fig. 5, and the calculated MO scheme presented in Fig. 4.

The interaction of nitrogen $2 p$ electrons with titanium $3 d$ electrons leads to two unoccupied molecular orbitals with $t_{2 \mathrm{~g}}$ and $e_{\mathrm{g}}$ symmetry, 2.7 and $4.3 \mathrm{eV}$ above the Fermi level, respectively. For the electron excitation process from atomic

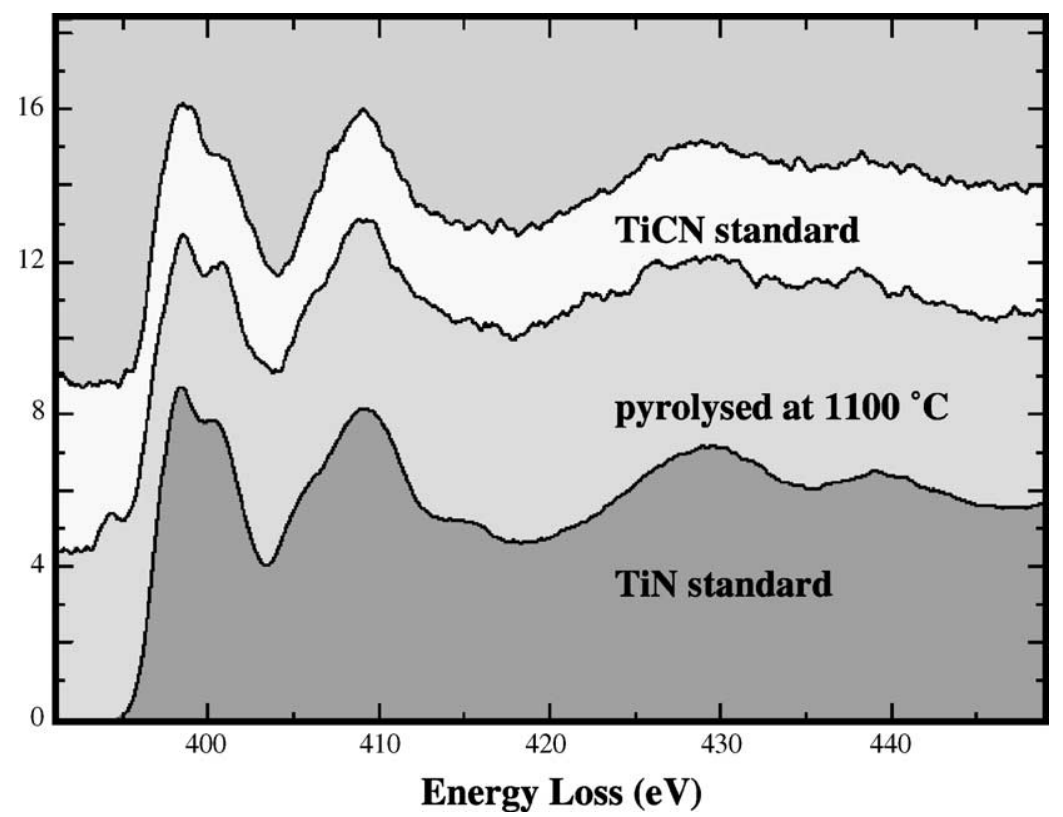

Fig. 5. ELNES of nitrogen in the reaction product of carbodiimidee pyrolysed at $1100{ }^{\circ} \mathrm{C}$, compared to those of $\mathrm{TiC}_{0.5} \mathrm{~N}_{0.5}$ and $\mathrm{TiN}$ standards (measured in arbitrary units). 


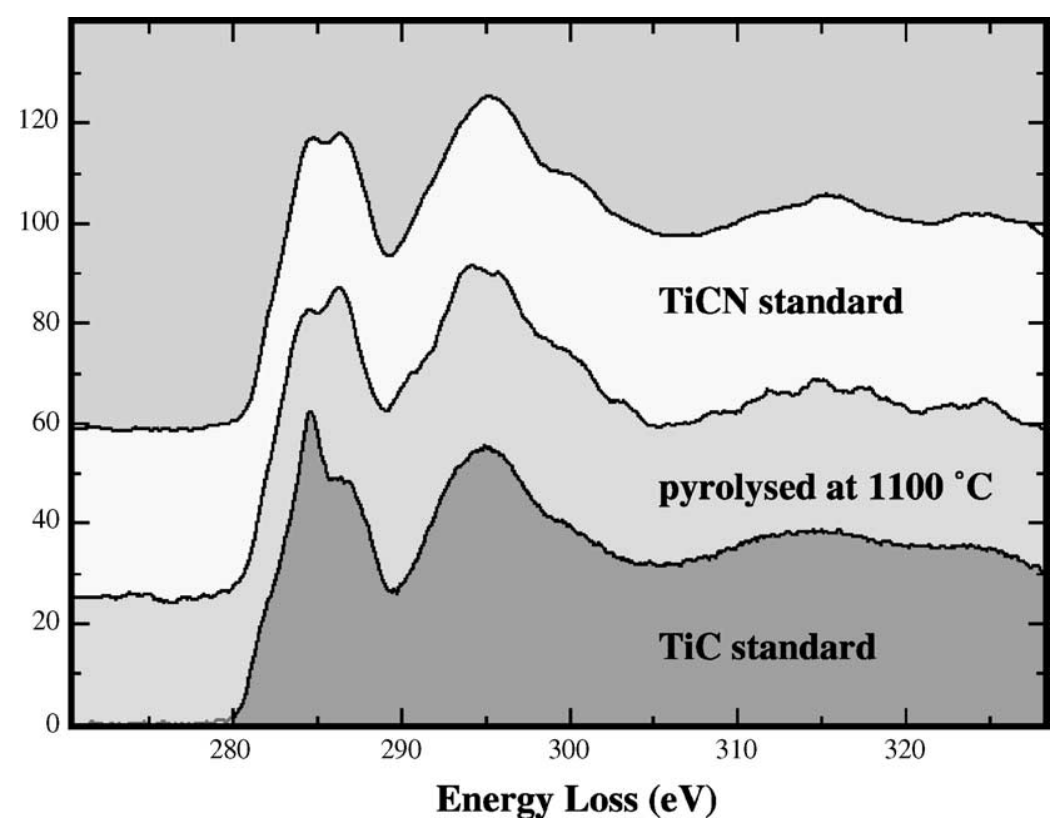

Fig. 6. ELNES of carbon in the reaction product of poly(titanylcarbodiimide) pyrolysed at $1100^{\circ} \mathrm{C}$, compared to those of $\mathrm{TiC}_{0.5} \mathrm{~N}_{0.5}$ and $\mathrm{TiC}$ standards (measured in arbitrary units).

core levels, the optical selection rules apply accordingly in our case (suppositions: forward scattering, fast electrons, cf. [13]), i.e. an electron with an angular quantum number of $l$ is excited into an energy level with the quantum number $l \pm 1$ with high probability. As both types of MOs contain contributions of p-like atomic orbitals (AOs) having the angular quantum number $l=1$, an excitation of an 1s-electron $(l=0)$ into these MOs will give rise to two observable peaks in the ELNES of the N-K edge: the excitation of nitrogen 1s-electrons into these two unoccupied MOs leads to the observed splitting of the peak at about 398.5 and $400.5 \mathrm{eV}$ in the measured EEL spectrum (cf. Fig. 5, bottom). The subsequent main peak at about $408.5 \mathrm{eV}$ results from the excitation of a $\mathrm{N} 1$ s electron in empty states with $2 \mathrm{p}-, 3 \mathrm{p}-$ and 3d-like symmetry, localised at the nitrogen atom.

After pyrolysis at $1100^{\circ} \mathrm{C}$ the ELNES of the $\mathrm{N}-\mathrm{K}$ edges remains similar to that observed after pyrolysis at $800^{\circ} \mathrm{C}$, i.e. it resembles that of titanium nitride again (cf. Fig. 5), but, the ELNES of the $\mathrm{C}-\mathrm{K}$ edge considerably changes: that is, the $\mathrm{C}-\mathrm{K}$ edge resembles that of titanium carbide now (cf. Fig. 6). It is characterised by a similar splitting of the first peak into two peaks at about 284.5 and $286 \mathrm{eV}$, assigned to the excitation of $\mathrm{C} 1 \mathrm{~s}$ electrons in two unoccupied MOs with $t_{2 \mathrm{~g}}$ and $e_{\mathrm{g}}$ symmetry, respectively (cf. the MO scheme in Fig. 4). However, a remarkable difference between the observed ELNES of the pyrolysed material and the C-K ELNES of titanium carbide is the intensity ratio of the first two peaks. In titanium carbide, the very first peak at about $284.5 \mathrm{eV}$ shows a significantly higher intensity than the second one at about $286 \mathrm{eV}$ (cf. Fig. 6, bottom). Contrary, the ELNES of the material pyrolysed at $1100^{\circ} \mathrm{C}$ shows an inverted intensity ratio of these two peaks. A comparison with the $\mathrm{C}-\mathrm{K}$ ELNES of a titanium carbonitride standard (Fig. 6, above) indicates a carbonitride phase in the pyrolysed material as confirmed by quantummechanical calculations.

The reason for such a different intensity ratio of the first two peaks in the C-K ELNES of TiC and TiCN is the inverted ratio of the occupation densities of the corresponding unoccupied MOs. For orthonormalised atomic wavefunctions the occupation densities are the squares of the orbital

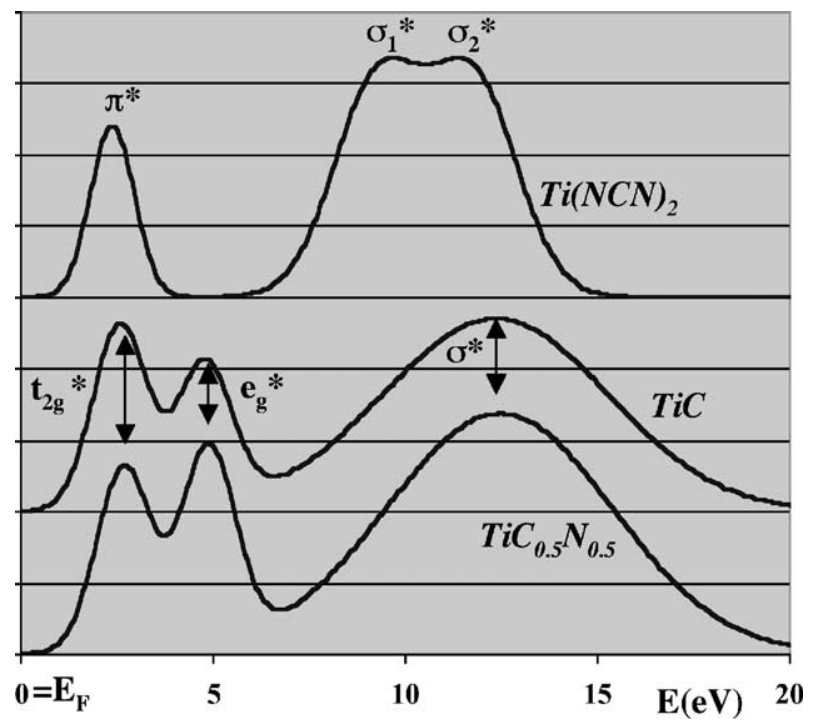

Fig. 7. Simulated shape of the C-K ELNES (intensity vs. energy above the Fermi level). Energies and occupation densities derived by DFT calculations. 
coefficients $c_{i \lambda}$ in the LCAO approach (2). The simulation of the $\mathrm{C}-\mathrm{K}$ ELNES for $\mathrm{TiC}$ and $\mathrm{TiC}_{0.5} \mathrm{~N}_{0.5}$ in consideration of the energies of the unoccupied levels as well as their occupation densities, obtained by DFT calculations is shown in Fig. 7.

A comparison of the experimentally measured $\mathrm{C}-\mathrm{K}$ ELNES of both, the sample pyrolysed at $1100^{\circ} \mathrm{C}$ and the $\mathrm{TiC}_{0.5} \mathrm{~N}_{0.5}$ standard (cf. Fig. 6), with the quantummechanical simulation shown in Fig. 7 proves the formation of titanium carbonitride at higher pyrolysis temperatures. This result is in good agreement with the observation of single crystals, containing nitrogen and carbon in equimolar amounts, described in Section 4.1. and shown in the high-resolution electron micrograph (Fig. 2b).

\section{Conclusions}

Nanocrystalline titanium carbonitride materials can be synthesised at pyrolysis temperatures of about $1100^{\circ} \mathrm{C}$ via a polymer-to-ceramic transformation of a titaniumcarbodiimide polymer. After cross-linking at $200^{\circ} \mathrm{C}$ it appears as amorphous powder with characteristic electron energy loss spectra, indicating the typical electronic structure of the carbodiimide bond (carbon with two double bonds to nitrogen). Pyrolysis of this polymeric material at $800^{\circ} \mathrm{C}$ under inert gas leads to a mixture of amorphous carbon and titanium nitride as very small crystalline particles $\left(4-5 \mathrm{~nm}\right.$ in size). Pyrolsis at $1100^{\circ} \mathrm{C}$ yields titanium carbonitride as crystalline particles of $20-30 \mathrm{~nm}$ in size.

The identification of all above mentioned phases $\left\{\left[\mathrm{Ti}(\mathrm{NCN})_{2}\right]_{n}\right.$, TiN, $\left.\mathrm{TiC}_{0.5} \mathrm{~N}_{0.5}\right\}$ succeeded by the analysis of the ELNES of their $\mathrm{C}-\mathrm{K}$ and $\mathrm{N}-\mathrm{K}$ edges, by comparison with measured standards as well as with simulated fine structures using DFT calculations.

\section{Acknowledgements}

The authors thank the Deutsche Forschungsgemeinschaft, Bonn and the Fonds der Chemischen Industrie, Frankfurt for financial support.

\section{References}

[1] R. Riedel, W. Dressler, Ceram. Int. 22 (1996) 233.

[2] R. Riedel, Naturwissenschaften 82 (1995) 12.

[3] K.J. Wynne, Ann. Rev. Mater. Sci. 14 (1984) 297.

[4] H.P. Baldus, M. Jansen, Angew. Chem. 109 (1997) 338.

[5] M. Herrmann, B. Balzer, C. Schubert, W. Hermel, J. Eur. Ceram. Soc. 12 (1993) 287.

[6] A.W. Weimer (Ed.), Carbide, Nitride and Boride Materials Synthesis and Processing, Chapman \& Hall, London, 1997.

[7] N. Hering, K. Schreiber, R. Riedel, O. Lichtenberger, J. Woltersdorf, Appl. Organometal. Chem. 15 (2001) 879.

[8] W. Verbeek, Offenlegungsschrift 2218960 (1973).

[9] W. Verbeek, U.S. Patent 3853567 (1974).

[10] S. Yajima, K. Okamura, S. Hayashi, Chem. Lett. 12 (1975) 1209.

[11] A. Greiner, Ph.D. Thesis, TU Darmstadt, 1997.

[12] I.A. Vostokov, I.Yu. Dergunov, A.S. Gordetsov, Zh. Obshch. Khim. 47 (1977) 1769.

[13] R.F. Egerton, Electron Energy-Loss Spectroscopy in the Electron Microscope, Plenum Press, New York, London, 1996.

[14] E. Pippel, J. Woltersdorf, G. Pöckel, G. Lichtenegger, Mater. Charact. 43 (1999) 41.

[15] R. Schneider, O. Lichtenberger, J. Woltersdorf, J. Microsc. 183 (1996) 39.

[16] E. Pippel, O. Lichtenberger, J. Woltersdorf, J. Mater. Sci. Lett. 19 (2000) 2059.

[17] G. Levy, W.D. Kaplan, M. Bamberger, Mater. Lett. 35 (1998) 344.

[18] J.J.P. Stewart, in: K.B. Lipkowitz, D.D. Boyd (Eds.), Reviews in Computational Chemistry, VCH Publishers, Weinheim, 1990.

[19] O. Lichtenberger, A. Beckmann, Phys. Stat. Sol. (a) 130 (1992) 125.

[20] O. Lichtenberger, R. Schneider, J. Woltersdorf, Phys. Stat. Sol. (a) 150 (1995) 661.

[21] R. Riedel, A. Greiner, G. Miehe, W. Dreßler, H. Fueß, J. Bill, F. Aldinger, Angew. Chem. 109 (1997) 657.

[22] O. Lichtenberger, J. Woltersdorf, N. Hering, R. Riedel, Z. Anorg. Allg. Chem. 626 (2000) 1881. 